\title{
A FAMILY SET METHOD FOR ESTIMATING HEREDITY AND STRESS-I
}

\author{
A PILOT SURVEY OF BLOOD PRESSURE AMONG NEGROES IN HIGH \\ AND LOW STRESS AREAS, DETROIT, 1966-1967
}

\author{
Ernest Harburg,* Ph.D., William J. Schull, $\dagger$ Ph.D., John C. Erfurt \\ and M. AnTHONY SCHORK, § Ph.D.
}

(Received 19 November 1968; in revised form 23 April 1969; further revised 3 Novernber 1969)

\begin{abstract}
AMERICAN Negroes have higher blood pressures at all age-sex levels than whites, higher rates of hypertensive heart disease, and higher mortality from hypertension and stroke [1]. Assessment of the relative contributions, if any, of sociopsychological stress, health risk, and genetic factors to these differences has been limited. Though certain evidence suggests that sociopsychological stress is associated with hypertension $[2,3]$ there is little understanding of the relationship of various forms of such stress to blood pressure. Similarly, while much evidence suggests that high blood pressure is "familial," little or no data are available which permit quantitation of the genetic component. The broad aims of this pilot survey, therefore, were both methodological and substantive. We sought a method of inquiry which permits concurrent testing of medical, environmental, sociopsychological, and genetic hypotheses, and would be of particular use in studies of different populations and diseases posing multifactorial problems. We further sought to explore whether or not differences in blood pressure levels might exist among Negroes residing in high and low stress census tracts. This report will describe the research design by which these aims were carried out, and present preliminary data testing the design in a pilot survey.
\end{abstract}

\section{METHOD}

\section{Design of the pilot survey}

Briefly, the design of the pilot survey was as follows:

(1) Two predominantly Negro census tracts in Detroit were selected as having extreme degrees of "ecological stress." The latter was defined to be a function of the socio-economic level, crime rate, residential change, family breakdown, and overcrowding in the area. The two selected census tracts are termed "high stress" and "low stress" and will be further described later in this article.

*Research Associate, Department of Psychology, The University of Michigan.

†Professor of Human Genetics, Medical School and Professor of Anthropology, College of Literature, Science and the Arts, The University of Michigan.

$\$$ Research Associate, Department of Psychology, The University of Michigan.

\$Associate Professor of Biostatistics, School of Public Health, The University of Michigan. 
(2) Within each stress area, a census was taken and from the census forms a random selection was made of "Index Cases," who were persons between the ages of 30 and 54, who were married and living with their spouse. The Index Cases also were required to have both a sibling (brother or sister), and a first cousin living in the city whose ages were within $5 \mathrm{yr}$ of the Index Case. From the same pool of Index Cases, an Unrelated Person was then selected, matched to the Index Case by age, sex, race, residence in the same area, marital status, and having the same available relatives. A complete "family set" therefore was composed of the following 5 persons: Index Case, Sibling, First Cousin, Index's Spouse, and an Unrelated Person. Within each family set, the Sibling and First Cousin provide the different degrees of genetic relationship necessary to construct a genetic variable.* The Spouse acts as a control for the "local environment" around the Index Case, e.g., diet, air, and water conditions. The Unrelated Person serves as a control for other critical environmental factors outside the "family" but within the same residential area as the Index Case and Spouse.

(3) A trained nurse-interviewer was sent to the home of each family set member to obtain 5 blood pressure readings and a $1 \frac{1}{2} \mathrm{hr}$ interview. The interview was designed to obtain the individual's medical history and to measure the amount of personal stress perceived in certain areas of life-economic, family, residential, and interpersonal.

Because this design necessitated a variety of pretesting in many different methods, it was decided to limit the pilot survey to Negro respondents and omit comparison with Caucasians. Further, the high stress Negro tract was characterized by low educational levels and a greater frequency of residential mobility and marital instability relative to all other tracts in the city of Detroit; it was presumed that if family sets could be obtained under these conditions, they could be obtained under less adverse ones. The target was to collect data on 52 family sets, or 260 respondents ( 5 members to a set). Twenty-six index cases, 13 male and 13 female, were to be selected from each of the 2 stress areas.

The specific objectives of the pilot survey were to: (1) devise an objective procedure for selecting census tract areas which varied in stress and which could be repeated in other major urban areas; (2) develop objective and inexpensive sampling procedures to first "screen" for index cases having family sets, then to randomly select index, siblings, cousins, and unrelated persons; (3) determine what proportion of persons have such family sets and the methods required to find them and obtain cooperation and interviews; (4) develop standardized techniques for interviewing and for measuring blood pressure in order to maximize comparability with other studies [4]; and finally, (5) develop and test our statistical models and prepare programs for the IBM 360 computer system. This report will deal with these objectives.

It cannot be overly emphasized here that all results are tentative and preliminary; more critical testing will be carried out with larger numbers in another study presently underway. This pilot survey then was conducted in cooperation with 400 Negro residents of "high stress" and "low stress" census areas in Detroit during October, 1966 to February, 1967.

\section{Selection of ecological stress areas}

There is much evidence that Negroes residing in "inner city" areas exist in an environment that is sharply different from the "outer city" and suburban areas. The

\footnotetext{
*The reader is referred to the second article in this series for an explanation of this genetic variable.
} 
latter areas exhibit performance rates in educational, recreational, sanitary, and service facilities which indicate attainment of high levels of living. Conversely, inner city areas exhibit sharply lower attainment levels and in addition repeatedly manifest higher rates of crime, divorce, unemployment and population density than outer city areas [5, 6]. Detroit is no exception to these contrasts [7]. It is assumed that such statistically different rates, at their end-points, indicate environments which vary objectively in chronic exposures to stressor events. We will call such kinds of different environments, high and low stress areas.

Briefly, all the census tracts of Detroit were rank ordered by their "stress scores" [8]. These scores were computed as follows: first, the rates for selected variables which represented the concepts of economic deprivation, residential instability, family instability, crime, and density were computed for each census tract in the city. These rates were then factor analyzed and factor scores were computed by Harmon's Method of Complete Estimation [9] for each tract. A "high" score indicated high stress. For the pilot survey, only those tracts having a predominantly Negro population were rank ordered by their stress scores. Tracts in the upper and lower quartiles were further selected by other criteria required by the family set design, e.g., percentage of dwelling units having married heads, Negro, between the age of 30 and 54 . Table 1 indicates the five major components of ecological stress, the variables which measure them, and the differing rates which characterized the two census tracts finally selected for the pilot survey. Partial validation of the level of stress in the high stress tract, the "12th Street" area, was provided by the "Detroit Rebellion" which began in this neighborhood in July, 1967 [10].

\section{Sampling procedures}

Once the 2 census areas were selected, a census of all dwelling units was conducted in each tract to describe the general tract populations and to screen for those persons having "family sets." During the six weeks of the census we were unable to contact 18 per cent (335) and 6 per cent (110) of the dwelling units in the high and low stress tracts, respectively. But of those dwelling units ascertained as Negro-occupied, (70 per cent in each area) 93 per cent (1209) and 96 per cent (1092) were interviewed. Interviews took $\sim 5 \mathrm{~min}$ and were conducted by trained college students, all Negro, from Wayne State University.* Each census form supplied information about the number of adults in the house, their age, sex, marital status, education, and occupation. For head or spouse only, data were gathered concerning the number and age of siblings and first cousins residing in the city or nearby area. While we preferred to interview either the head or spouse, available persons over 21 who were family members were accepted as respondents in the census.

\section{The feasibility of sampling family sets}

The idea of sampling index cases, aged 30-54, living with their spouses and having siblings and cousins within a 5-yr age range, was hased on previous work with "family sets" [11]. The present study has modified the prior design and shifted the geographic focus from a national survey to an urban area. Nevertheless, in 1966 no data were available on the number and proprtion of family sets available in Detroit and no

*Much appreciation goes to Mr. Eugene Beauregard for assistance during the initial phase of field work. 
Table 1. High and LOW StRess census tracts in the Study By Key eCological Variables, DETROIT, 1965*

\begin{tabular}{|c|c|c|c|}
\hline & Ecological variable & $\begin{array}{l}\text { High stress } \\
\text { census tract }\end{array}$ & $\begin{array}{l}\text { Low stress } \\
\text { census tract }\end{array}$ \\
\hline \multirow[t]{4}{*}{1.} & Economic deprivation & & \\
\hline & Median income & $\$ 4000$ & $\$ 7666$ \\
\hline & Median number of school years completed & 10.5 & 13.1 \\
\hline & Percentage of unemployment & 10 & 2 \\
\hline \multirow[t]{4}{*}{2.} & Residential instability & & \\
\hline & Percentage of persons living in the same house for & & \\
\hline & last $5 \mathrm{yr}$ & 36 & 55 \\
\hline & Percentage of owner-occupied dwelling units & 17 & 63 \\
\hline \multirow[t]{2}{*}{3.} & Family instability & & \\
\hline & $\begin{array}{l}\text { Ratio of the number of separations and divorces to the } \\
\text { number of marriages }\end{array}$ & $1: 5$ & $1: 20$ \\
\hline \multirow[t]{7}{*}{4.} & Crime (per 1000 population) & & \\
\hline & Rate of juvenile offenses against persons & 5.1 & 2.0 \\
\hline & Rate of juvenile offenses against property & 11.6 & 1.4 \\
\hline & Rate of juvenile offenses against institutions & 3.5 & 1.4 \\
\hline & Rate of adult offenses against persons & 43.3 & 2.3 \\
\hline & Rate of adult offenses against property & 78.9 & 24.0 \\
\hline & Rate of adult offenses against institutions & 14.7 & 1.1 \\
\hline \multirow[t]{7}{*}{5 . } & Density & & \\
\hline & Number of persons per residential acre & 137 & 46 \\
\hline & Population & & \\
\hline & Total population & 4893 & 5632 \\
\hline & Percentage of Negroes in population & 98 & 77 \\
\hline & Total number of occupied households & 1614 & 1790 \\
\hline & Percentage of Negro-occupied households & 98 & 67 \\
\hline
\end{tabular}

*Data from a 4 per cent sample of the Detroit area from the Transportation and Land Use Study (1965); crime data were obtained from the Detroit Department of Police and the Detroit Youth Bureau.

repeatable sampling method had been developed. The pilot survey has provided both the data and a method. These findings are confined in sensu strictu to results in 2 census tracts in Detroit having predominantly Negro populations; nevertheless, within certain limits, the evidence is persuasive that these results apply to other comparable census tract areas as well.

One major problem in collecting "family sets" involves ascertaining the "true" genetic relationships between the index cases and their siblings and first cousins. Illegitimacy and common-law marriages are higher among working class than middle class groups, and especially high among working class Negro groups [7]. The problem of "true" relationships is confounded with obtaining a complete listing of "true" siblings and first cousins. Both problems were attacked through designing a number of checks in the method of obtaining such lists. First, initial data on the presence of relatives were taken by the census interviewer. Next, those persons who had family sets were revisited by a "verifier" who obtained the names of relatives, exact relationships, age, sex, and address in the city. During the third and final contact by the nurseinterviewer, the index person was again asked to list the names and ages of all his siblings. This list, in turn, was again checked with his sibling's listings, now independently obtained by another nurse in her interview with that sib. As with the index and sibling, the verifier also checked the first cousin's age, sex, and relationship to 
the index case; these data were then again checked independently by the nurseinterviewer. In all cases, direct questions were asked regarding "blood line" between the index case and the sibling and first cousin. If there was any indication of "half", "secondary", "doubtful", or even no relationship, efforts were made to find a fully verified relative, or the set was dropped. An empirical test of the success of this approach is the correlation of the genetic variable with known genetic markers. Even with a significant positive correlation, of course, the degree of error is not known, but it may be assumed that this error is not large enough to vitiate other important comparisons.

The first question to be answered was what number and proportion of married persons, 30-54 yr old, residing in the City of Detroit, had siblings and cousins within five years of their age who were also residing in the city? An earlier study by Aiken [12] of a representative sample of largely white housewives in Detroit reported that: (1) 50 per cent of their siblings lived in Detroit; (2) 50 per cent of their "cousins" lived in Detroit; and (3) only 10 per cent of the sample had "no relatives" in the city. The results of the present study are shown in Table 2. In both census tracts, about 55 per cent of all husbands and wives reported having at least one sibling living in Detroit; 39 per cent of all persons reported having first cousins living in Detroit. Thus, these data compare reasonably well with Aiken's figures from a sample of the city.

TABLE 2. THE FEASIBILITY OF OBTAINING FAMILY SETS IS SUPPORTED BY THESE DATA SHOWING THAT OF ALL THE HUSBANDS OR WIVES ANSWERING THE CENSUS FORM IN EACH OF THE TWO TRACTS, A SUFFICIENT PERCENTAGE DID INDEED HAVE SIBLINGS AND FIRST COUSINS WITHIN 5 YR OF AGE LIVING IN DETROIT

\begin{tabular}{|c|c|c|c|c|c|c|c|c|}
\hline & \multicolumn{4}{|c|}{ Have sibs in Detroit } & \multicolumn{4}{|c|}{ Have sibs, $\pm 5 \mathrm{yr}$ in Detroit } \\
\hline & \multicolumn{2}{|c|}{ High stress } & \multicolumn{2}{|c|}{ Low stress } & \multicolumn{2}{|c|}{ High stress } & \multicolumn{2}{|c|}{ Low stress } \\
\hline & $(\%)$ & $(N)$ & $(\%)$ & $(N)$ & $(\%)$ & $(N)$ & $(\%)$ & $(N)$ \\
\hline $\begin{array}{c}\text { None } \\
1 \\
2 \\
3+ \\
\text { DK* }\end{array}$ & $\left.\begin{array}{l}44 \\
19 \\
12 \\
24\end{array}\right\} 55$ & $\begin{array}{r}(572) \\
(243) \\
(151) \\
(310) \\
(6)\end{array}$ & $\left.\begin{array}{l}41 \\
23 \\
13 \\
22\end{array}\right\} 58$ & $\begin{array}{r}(634) \\
(341) \\
(194) \\
(336) \\
(3)\end{array}$ & $\left.\begin{array}{l}53 \\
21 \\
12 \\
12 \\
2\end{array}\right\} 45$ & $\begin{array}{r}(690) \\
(265) \\
(151) \\
(152) \\
(24)\end{array}$ & $\left.\begin{array}{l}55 \\
22 \\
11 \\
10 \\
2\end{array}\right\} 43$ & $\begin{array}{c}(834) \\
(332) \\
(173) \\
(139) \\
(30)\end{array}$ \\
\hline \multirow[t]{3}{*}{ Total } & 100 & $(1282)$ & 100 & (1508) & 100 & (1282) & 100 & (1508) \\
\hline & \multicolumn{4}{|c|}{ Have first cousins in Detroit } & \multicolumn{4}{|c|}{ Have first cousins, $\pm 5 \mathrm{yr}$ in Detroit } \\
\hline & $\begin{array}{l}\text { High } \\
(\%)\end{array}$ & $\begin{array}{l}\text { ress } \\
(N)\end{array}$ & $\begin{array}{l}\text { Low s } \\
(\%)\end{array}$ & ess & $\begin{array}{c}\text { High } \\
(\%)\end{array}$ & ess & $\begin{array}{l}\text { Low s } \\
(\%)\end{array}$ & ess \\
\hline $\begin{array}{c}\text { None } \\
1 \\
2 \\
3+ \\
\text { DK* }^{*}\end{array}$ & $\left.\begin{array}{r}55 \\
11 \\
6 \\
22\end{array}\right\} 39$ & $\begin{array}{c}(700) \\
(143) \\
(71) \\
(379) \\
(83)\end{array}$ & $\left.\begin{array}{c}52 \\
10 \\
6 \\
23 \\
9\end{array}\right\} 39$ & $\begin{array}{r}(779) \\
(154) \\
(86) \\
(349) \\
(130)\end{array}$ & $\left.\begin{array}{c}66 \\
9 \\
4 \\
12\end{array}\right\} 25$ & $\begin{array}{l}(831) \\
(120) \\
(52) \\
(160) \\
(112)\end{array}$ & $\left.\begin{array}{c}61 \\
8 \\
5 \\
13 \\
13\end{array}\right\} 26$ & $\begin{array}{l}(921) \\
(125) \\
(68) \\
(194) \\
(190)\end{array}$ \\
\hline Total & 100 & $(1275)$ & 100 & (1498) & 100 & $(1275)$ & 100 & (1498) \\
\hline
\end{tabular}

* "DK" means that the person answering the census said they did not know whether they or their spouse had such a relative in Detroit or did not know the age. Approximately 50 per cent of persons selected in the sample, who were "DK" on the Census Form, actually had a Family Set when visited later by the verifier. 
Table 2 also shows figures which are of greater relevance to the specific aims of this study. These figures disclose that, in both tracts, about 45 per cent of the people reported having a sibling within $5 \mathrm{yr}$ of age living in Detroit. The latter per cent is variable because about 50 per cent of the persons who said they "didn't know" whether they had one or more first cousins or their ages did in fact have such relatives on further search.

Data in Table 3 reveals 2 further lines of evidence pertinent to the feasibility of obtaining family sets. First, the figures indicate that fairly reasonable estimates of proportions of dwelling units having potential index persons can be made from census data and from a large sample study for both target tracts. Second, the last footnote in Table 3 indicates that about one-third of the dwelling units had potential index persons out of the total tract population of married, ages 25-59, and this percentage was similar for each of the 2 tracts, i.e. 33 per cent and 31 per cent. This is important because a figure of 33 per cent had been assumed to make prior

TABle 3. Comparisons of THE ESTIMATES AND ACTUAL PERCENTAGE AND NUMBER OF NeGRO-OCCUPIED DWELLING UNITS (DU'S) WITH MARRIED HOUSEHOLD HEADS AND/OR WIVES HAVING FAMILY SETS BY CENSUS TRaCT, DetroIT, 1966

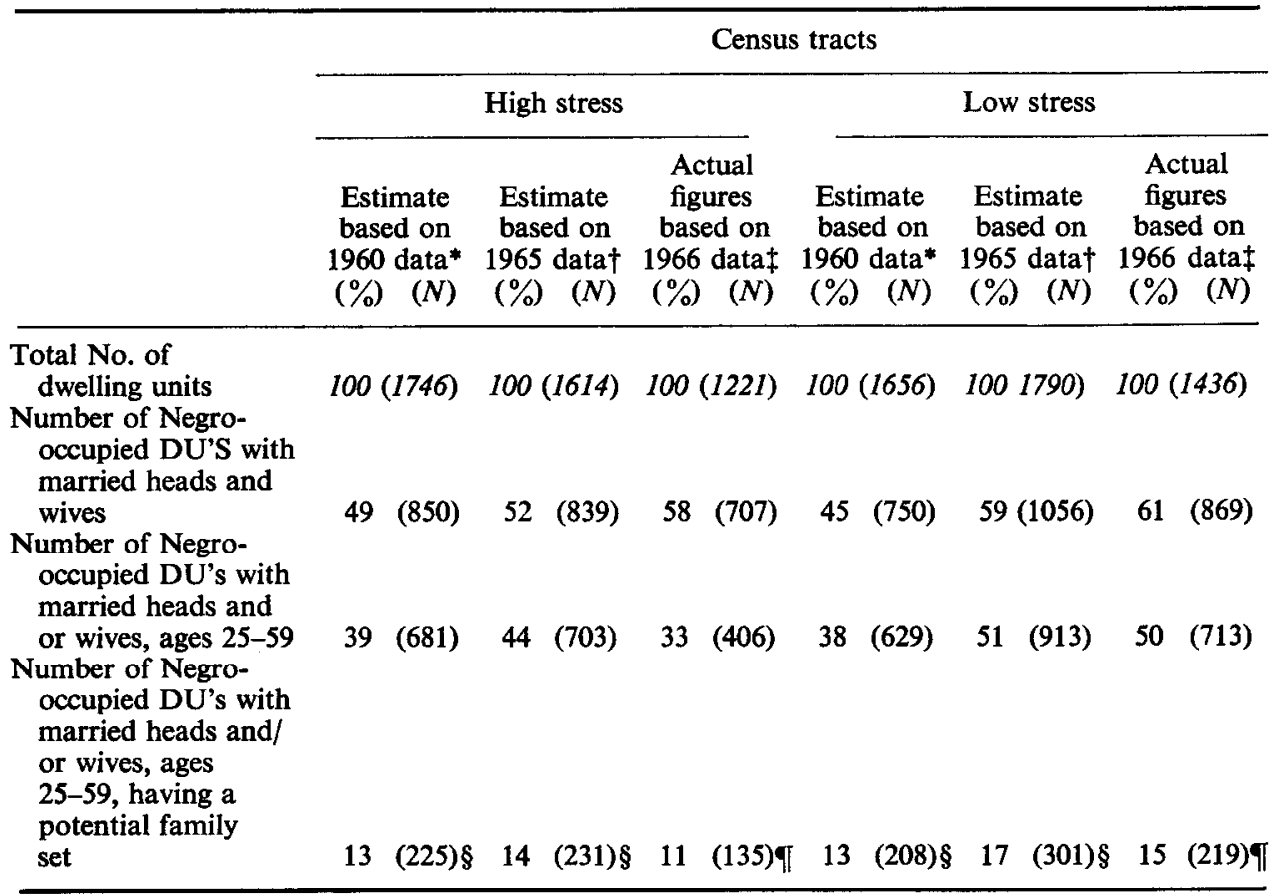

*U.S. Census Data (1960).

†Data from a 4 per cent sample of the Detroit Area by the Transportation and Land Use Study (1965). †Screening data collected by our Project Census, August-September, 1966; the total includes those dwelling units which were (a) ascertained as non-Negro, and (b) ascertained as Negro and successfully screened.

\$This estimate is based on the assumption that in 33 per cent of the Negro-occupied DU's with married heads and/or wives, ages $25-59$, one or both of these persons will have a potential family set. 7The actual data show the percentage of DU's with Negro heads and/or wives, ages 25-59, having potential family sets of the total number of DU's with heads and/or wives, ages 25-59 to be 33 per cent in the high stress tract and 31 per cent in the low stress tract. 
estimates of this population. The actual data show a strong fit with this assumption which was based on Aiken's [12] 1955 results. The evidence is thus highly suggestive that similar results can be achieved in other areas of Detroit.

The next major question is how can an adequate sample of index and unrelated persons actually be obtained? Three steps are required to obtain a listing of such a population. First, some screening of a given community of people must be made. Here, a full census was taken. Next, all those persons who fit the criteria of potential index case must be interviewed and their status verified. This will eliminate false positives, which in the pilot survey occurred about 25 per cent of the time. This procedure, of course, cannot check false negatives. Third, search operations for hard-to-find index persons must be systematic and persistent. Once the basic population list, or universe of potential index persons, is compiled, a random sample of index persons and their unrelated controls can then be drawn. Using this design the index person and his matched control are drawn from the same universe and are in effect randomly assigned to their family set roles. If the index case has more than one sibling or first cousin within five years of the index person's age and living in Detroit, then that sib nearest in age to the index person is selected. It might be noted that multiple siblings and first cousins occurred in 45 per cent and 43 per cent, respectively, of all cases. Practically all of the siblings and first cousins lived outside the 2 stress tracts where the index, spouse, and unrelated persons resided.

Next, one must ask, how does the sample of index persons and their unrelated controls compare to the population of all other married persons in the area on important social criteria? Data, not shown, indicate that the pilot survey sample did not differ significantly within sex categories from the tract population in age, education, and socioeconomic status in the high stress area and differed only slightly on these variables in the low stress tract. In the low stress area, the males in the sample tended to be somewhat younger with more education than those in the population; also, there were somewhat fewer housewives among the females in the sample than in the tract population.

Finally, what about the index persons selected for the sample but not interviewed? How different were they in age, education, and socioeconomic status from those individuals actually interviewed? Data, not shown, are clear that such persons showed no significant differences within sex categories on these major variables across all comparisons. It must be noted that the last 2 questions cannot be answered precisely in the usual random-sample survey. Through use of a census or "screening", however, one collects data on the entire population of household heads and their wives in the given social area and can test directly the similarity of the area population to the sample in regard to critical variables. The use of a census also permits matching the unrelated person to the index person more precisely with regard to age, race, sex, area, marital status, and existence of a family set. In short, the evidence collected and the methods developed in the pilot survey encourage further work.

\section{The pilot survey sample}

The number of respondents in the pilot survey was, of course, small; the major objective was to obtain interviews and blood pressure readings among members of 52 family sets. Table 4 indicates that slightly more (56) than the planned number of family sets were obtained: 26 in the high stress tract, and 30 in the low stress tract. 
Approximately half of the index cases in each tract were male, and half were female, with the mean ages of the index persons closely matched $( \pm 4 \mathrm{yr})$ to their siblings first cousins, and the unrelated persons. The mean age of the spouse varies in the expected direction in that the husbands' ages are greater than the wives'. These differences are greater in the high stress area than in the low stress area, with the latter differences only about $3 \mathrm{yr}$. In summary, a sample was drawn of Negro persons aged 30-54, who were married and living with their spouses in a given census area, and who had siblings and cousins living in Detroit. It can also be said that we have interviews with 280 members of 56 family sets.

\section{The design of the interview}

Each member of the 56 family sets ( $280+$ persons) was visited at his or her home by a public health nurse, well-trained in survey interviewing and a standard blood pressure procedure.* Interviewers were matched by race with the respondent. An hour and a half interview was conducted. During the first half hour, three blood pressures were taken and in the last $10 \mathrm{~min}, 2$ more were read.

TAble 4. Number of family SETS By CENSUS TRACT, SEX OF INDEX PERSON, NUMber, AND MEAN AGE OF SET MEMBERS-PILOT SURVEY, 1966-1967

\begin{tabular}{|c|c|c|c|c|c|c|c|c|c|}
\hline \multirow[b]{5}{*}{ Family set members } & \multicolumn{8}{|c|}{ Census tract } & \multirow{5}{*}{$\begin{array}{l}\text { No. of } \\
\text { persons } \\
\text { inter- } \\
\text { viewed }\end{array}$} \\
\hline & \multicolumn{4}{|c|}{ High stress } & \multicolumn{4}{|c|}{ Low stress } & \\
\hline & \multicolumn{4}{|c|}{$\begin{array}{l}\text { Family set where } \\
\text { index person is: }\end{array}$} & \multicolumn{4}{|c|}{$\begin{array}{l}\text { Family set where } \\
\text { index person is: }\end{array}$} & \\
\hline & \multicolumn{2}{|c|}{ Male } & \multicolumn{2}{|c|}{ Female } & \multicolumn{2}{|c|}{ Male } & \multicolumn{2}{|c|}{ Female } & \\
\hline & $N$ & $\begin{array}{c}\text { Mean } \\
\text { age } \\
(\mathrm{yr})\end{array}$ & $N$ & $\begin{array}{c}\text { Mean } \\
\text { age } \\
(\mathrm{yr})\end{array}$ & $N$ & $\begin{array}{c}\text { Mean } \\
\text { age } \\
(\mathrm{yr})\end{array}$ & $N$ & $\begin{array}{c}\text { Mean } \\
\text { age } \\
(\mathrm{yr})\end{array}$ & \\
\hline Index person & 12 & 42.0 & 14 & 38.1 & 14 & 38.9 & 16 & 40.6 & 56 \\
\hline Spouses of index person & 12 & 36.8 & 14 & 45.2 & 14 & 35.9 & 16 & 43.9 & 56 \\
\hline Siblings of index person & 12 & 41.5 & 14 & 36.6 & 14 & 38.7 & 16 & 40.7 & 56 \\
\hline First cousin of index person & 12 & 45.0 & 14 & 38.4 & 14 & 39.6 & 16 & 42.4 & 56 \\
\hline Control persons* & 12 & 42.8 & 14 & 38.8 & 14 & 38.0 & 16 & 41.2 & 56 \\
\hline Total persons & 60 & & 70 & & 70 & & 80 & & 280 \\
\hline Number of family sets $(N=56)$ & 12 & & 14 & & 14 & & 16 & & \\
\hline
\end{tabular}

*The control (unrelated person) is matched to the index case by sex, age, race, marital status, census area, and possession of a family set.

The interview explored the "personal stress" of the respondent in such areas as: (1) making a living; (2) marital and family relations; (3) early family life; (4) neighborhood living conditions; (5) race relations; (6) emotional responses to interpersonal and social relations; and (7) self-esteem. In the same interview, a brief medical history provided data on risk factors previously related to blood pressure: age, smoking, activity level, the person's and parents' cardiovascular disease history, cardiac awareness, height, weight, most ever weighed, and use of medical resources.

*Many thanks to Mrs. Mildred Harvin, our Nurse-Supervisor, who helped to develop and record this procedure, as well as to coordinate the field work. This procedure may be obtained by request. 


\section{FINDINGS}

\section{Preliminary results}

Table 5 shows that respondents in the high stress area did indeed report a higher degree of environmental threat and frustration than did persons in the low stress tract. For example, of the high stress residents, 91 per cent reported that they were likely to get robbed or beaten at night, yet only 22 per cent judged that the police would arrive within $10 \mathrm{~min}$ if a "breaking and entry" were reported; for low stress inhabitants, these figures were 42 and 48 per cent. Similarly, 84 per cent of the high stress persons said they did not like living in their neighborhood, and 92 per cent would like to move; for low stress persons, these figures were only 18 and 50 per cent.

Differences between high and low stress tract residents in proportions having hyper-

Tarif. 5. Percentage of Nfgro Respondents in high and low stress tracts rfplying to rtems ABOUT THEIR NEIGHBORHOOD AND PERCENTAGE HAVING HYPERTENSIVE BLOOD PRESSURE LEVELS, DETROIT, 1966*

\begin{tabular}{ccc}
\hline Collective responses & High stress & Low stress \\
census tract & census tract \\
$(N=102)$ & $(N=113)$
\end{tabular}

\section{Questionnaire items}

A. Neighborhood threat

1. Safety of neighborhood: percentage saying not too safe or not safe at all

2. Likely to get robbed/beaten at night: percentage saying somewhat or very likely

B. Public services last year: percentage saying Yes

4. Worry about fires in the neighborhood: Percentage saying saying somewhat or fairly often

1. Evaluation of the education children get from the public schools in the area: Percentage saying not too good or not good at all

2. Satisfied with recreation in area: Percentage saying not too satisfied or not satisfied at all

3. Likelihood of getting help from the city to improve neighborhood facilitics: Percentage saying not too likely or not at all

4. Time for police to arrive for call about housebreaking: Percentage saying $10 \mathrm{~min}$ or less

C. Residential stability

1. Percentage living $5 \mathrm{yr}$ or less at present address

2. Percentage moved two or more times in last $5 \mathrm{yr}$

3. Like living in neighborhood: Percentage saying not too much or not at all

4. Would like to move to different neighborhood: Percentage saying fairly or very much

D. Other variables

1. Mean weight (lb)

2. Mean age (yr)

3. Mean number of years at present residence II. Blood pressure levels

A. Per cent having hypertensive levels

$(160+$ and/or $95+\mathrm{mm} \mathrm{Hg})$
72

91

58

55

15

42

16

80

46

46

22

48

62

28

44

14

84

18

92

50

164

163

40.5

40.0

$6.1 \quad 7.3$

$31 \dagger$ per cent 18 per cent

*Data from questionnaire responses obtained in the pilot survey from respondents in the family set sample living in the two selected census tracts, i.e. the index cases, their spouses, and control cases. $+\mathrm{X}^{2}=4.72 ; p<0.04$. 
tensive levels of blood pressure were also significant and in the same direction, i.e. 32 per cent of the married sample in the high stress area had blood pressure levels of $160+/$ or $95+$ (average of first three readings) compared to 18 per cent of those in the low stress area. Neither age nor weight affected this finding. We also collected additional data from small independent random samples within each tract area of "nonmarried" females, 30-54 yr old, (mean age, about $40 \mathrm{yr}$ ) and the results, not shown, were similar, i.e. 38 per cent $(N=24)$ had hypertensive levels in the high stress area compared to 19 per cent $(N=21)$ in the low stress tract.

Analyses of the questionnaire items revealed that blood pressure levels were significantly correlated with different patterns of life stress for the essentially working class persons in the high stress area, and for the middle class persons in the low stress area. Briefly, working class persons in the high stress area with higher blood pressure levels (adjusted for sex, age and weight) reported greater economic frustration and more satisfaction (sic) with their marital life and their neighborhood than did their normotensive counterparts in the same tract. In contrast, middle class persons with higher blood pressure levels had higher occupational achievements and aspired to even more than did their normotensive neighbors. This latter pattern of "strivers" was also reported by Stamler [13]. Finally, regressions of the genetic variable on a crude rating of skin color and on reported height were statistically significant; however, several models used for analysing the relationship of this genetic variable with blood pressure levels were inconclusive [14].

\section{DISCUSSION}

While the proposed design has already withstood the perils of a small pilot study, there nevertheless exist several questions concerning the validity of its assumptions and the practicality of its operations. These questions may be grouped with reference to the major interdisciplinary problems involved-heritability, stress, and blood pressure.

Insofar as the major design will require comparison between two racial populations, the first question concerns the extent of genetic differences between American Negroes and American Caucasians. There appears to be a rough but general concensus emerging from a variety of studies of blood types [15] that about 22 per cent of the genes of the average American Negro are Caucasian in origin. Granted that an unknowable amount of miscegenation has occurred in American nation building, the predominant mating tradition in the United States has been and isintraracial: less than 1 per cent of all marriages in the United States are interracial, and this figure includes Oriental-Caucasian marriages. What about within races? Will a random selection of Caucasians in an urban area yield a population which is "homogenous" for sake of comparison? The design calls for each family to provide its own controls in the form of siblings and first cousins. The degree of genetic relationship with blood pressure within each family set is the basic statistical unit of analysis. Furthermore, by proper census tract selection and sampling of index cases we can assure a mix of ethnic groups of European origin in probably segregated Caucasian stress areas.

What about certain biases of ascertaining index cases and family set members? Certainly, it is true that by requiring that index persons have siblings we have already eliminated the "only child" as an index case and have thereby assured that the sampled families will be larger than "average". This would, of course, restrict the kinds of 
inferences which can be drawn from the sample results, but this would be a small cost to pay if the stated objectives can be achieved. Perhaps, however, persons in larger families where one member has high blood pressure will tend to be more cooperative and thereby bias the resultant sample of family sets, i.e. if the index case were to have high blood pressure, this might encourage cooperation of those siblings and first cousins who also have high blood pressure and thereby create spuriously high intrafamily genetic correlations. The same bias of selection might also influence completion of interviews with unrelated persons. There are a number of ways to ascertain the magnitude of this bias: the most obvious one is to test the blood pressure distributions between index cases and the four other family set members; such a test on this sample shows no differences in blood pressure levels. We have already discussed the problems of ascertaining "true" genetic relatives and of obtaining their cooperation.

It has also been pointed out that the design calls for comparisons between the index person and each of the other family set members regarding their blood pressure, and that measurement error of blood pressure is variable enough to limit the value of such comparisons. For example, it has been established that not only "digit preference", but time of day, number of hours since last meal, smoking, drinking, presence of others, recent shock and so forth all affect blood pressure readings [2]. Might not such "local noise" at the time of measurement create undue variability in levels thus making one-to-one interperson comparisons subject to much error? Each of the environmental and local errors mentioned can be measured and tested to expose their effects on group pressures; if necessary, such differences can be adjusted through covariance analyses in order to make the major test more precise. Careful training of nurse-interviewers in the techniques of a standardized blood pressure procedure should also reduce further artifactual differences.

While every effort was made to measure the genetic and blood pressure variables as validly and precisely as possible, no less effort was put into developing valid measures of stress. We have referred to the selection of high and low stress residential or census tract areas. These are objective procedures. Measurement of personal stress, however, requires verbal reporting varying in degree from "semi-objective" data such as age, occupation, marital status and so forth to "subjective" data such as one's feelings and attitudes. Unfortunately, there are no standardized tests or even sets of questions which validly or reliably measure the degree of "life stress" experienced by any given individual, especially as this may relate to blood pressure. Preliminary results from this pilot survey indicate that various measures of life stress are significantly related to blood pressure levels. These results, however, must be retested with larger numbers and on Negro and Caucasian populations.

The target in the larger study now ongoing, therefore, is to collect 100 index cases, spouses, and unrelated persons in each of four selected race-stress census areas in Detroit, i.e. Negro high and low stress areas and Caucasian high and low stress areas. $\Lambda$ s there are 5 members to a family set, and about a 20 per cent "over-sample" is required, we are now collecting blood pressure and interview data from about 2400 persons or 400 family sets.

The major hypotheses which this design allows us to test are (1) that blood pressure will vary with ecological stress. (2) It will vary with personal stress in making a living marital and family relations, early family life, neighborhood living conditions, race 
relations, responses to emotionally charged life situations, "status-striving", resentment, and self-esteem. (3) Blood pressure will also vary with known health-risk factors such as a family history of cardiovascular disorders, overweight, smoking habits, and infrequent use of medical aids. These measures of stress and health factors having been established, and the genetic variable constructed, the following general questions can then be explored with appropriate statistical models:

1. Is the dependence of blood pressure on the genetic scores the same within the 2 races?

2. Is the proportion of the total variability accountable for in terms of stress the same for each race?

3. Is there evidence of a stress-genotype interaction in either race which might suggest that one's response to stress varied as a function of his genotype?

4. What is the influence of health-risk factors on these relationships?

Finally, it should be noted again that our objectives are methodological as well as substantive. The primary effort is to develop a survey method to measure a genetic variable and sociopsychological aspects of the environment in a single operation. These measures, with given health variables, can be used to assess relative contributions not only to blood pressure but also to other diseases. While theoretically all such correlational findings can be explained by either genetic or sociopsychological hypotheses, the weight of evidence will favor that theory which predicts more precisely across several studies. In a future study, if medical examinations are given to a sufficient number of family sets, then physiological and chemical measures taken during the exam and predicted to be disease-related can be tested for their relationship in turn to both stress and genetic variables.

\section{SUMMARY}

A pilot survey designed to test the feasibility of measuring genetic and stress variables as they relate to blood pressure levels was carried out among Negroes residing in high and low stress census tracts in Detroit, 1966-1967. Fifty-six "family sets" or 280 persons were interviewed and blood pressure recordings were taken by trained nurses. Each family set was composed of an index, a spouse, a sibling and a first cousin of index, and an unrelated person in the census tract matched to index. The method and findings of obtaining such family sets is discussed and found to be encouraging enough to initiate a larger study. It was also found that proportions of persons with hypertensive levels were significantly greater in the high stress tract ( 32 per cent; $N=102$ ) than in the low stress tract (19 per cent; $N=113$ ).

Acknowledgments-A project as large as this must necessarily draw on the knowledge and skills of many agencies and persons. Acknowledgments of support to all is not possible; therefore the following list is a partial one.

Initial support in the form of seed money from the Office of Research Administration at The University of Michigan was critical in allowing this project to start. Dr. Samuel Fox's encouragement, funds from the Center for Chronic Disease Control. U.S. Public Health Service, and Mr. Robert Thorner's administrative skills within this Center, made this pilot survey viable.

Local resources of The University of Michigan in Ann Arbor have also been utilized in various ways with an equally high degree of cooperation. Informal consultation with a core group of authorities in ecology, biostatistics, hypertension, survey methods, sampling, and human genetics has been established for the duration of the Project. The computer facilities of The University of Michigan, the Institute for Social Research, and Wayne State University, including program consultation, have been used extensively. 
Active consultants to this Project include: Dr. Jeremiah Stamler, Dr. Sibley W. Hoobler, and Dr. Theodore M. Newcomb. Other persons informally consulted are: Dr. Frederick Epstein, Dr. Otis D. Duncan, Dr. J. E. Keith Smith, and Dr. John Scott. They each have contributed much to this Project. Our special thanks to Dr. Stevo Julius.

Cooperation from local agencies in Detroit has been superb. The Visiting Nurses Association and the City Department of Health were most helpful in recruitment, and in solving minor problems. The City of Detroit, Department of Police, has furnished through its statistical units all the crime and delinquency records requested, in an efficient and most pleasant manner. The Mayor's Committee for Community Renewal Program has been most helpful in every request for data, maps, etc., made by Project personnel. Wayne State University campus facilities and graduate students' aid were arranged by the Department of Sociology and Anthropology, which also allowed use of a field office in the department, and appointed the Project Director an Adjunct Professor. Wayne State University provided facilities for training purposes, and facilitated administrative matters. Other agencies aiding the Project were the City of Detroit Planning Commission and the Metropolitan Services Agency. Many persons in Detroit have been consulted on a variety of problems, and all have freely given of their time and ideas.

The twelve part-time public health nurses who actually collected the data through snow, rain and high stress areas all did an excellent job, guided by Mrs. Mildred Harvin, a superb Nurse-Supervisor.

Our Detroit Advisory Committee must be thanked for their time, helpful criticisms and support: Dr. Mel Ravitz, Mr. Francis Kornegay, Dr. John Caldwell, Miss Sylvia Peabody, Dr. Leonard Moss, Dr. Ross Stagner, Dr. Robert Smock, Mr. Homer Hall, and Dr. Milton Palmer.

Appreciation must also be expressed to Mr. William Ash, the mathematician-programmer who has served this project well since its inception.

Finally, we must express our appreciation for additional grant support during 1967-1968 to the Michigan Heart Association, which enabled final data analyses of the pilot survey and preparation for the larger study.

\section{REFERENCES}

1. Stamler J: Lectures in Preventive Cardiology. New York, Grune \& Stratton, 1967

2. Stamler J, Stamler R, Pullman TN: The Epidemiology of Hypertension. New York, Grune \& Stratton, 1967

3. Scotch NA, Geiger HJ: The epidemiology of hypertension: A review with special attention to psychologic and sociocultural factors-II. Psychologic and sociocultural factors in etiology. J Chron Dis 16: 1183-1213, 1963

4. Weinstein BJ, Epstein FH, et al: Comparability of criteria and methods in the epidemiology of cardiovascular disease. Circulation 30: 643-653, 1964

5. Bureau of Labor Statistics, No. 332: Social and economic conditions of Negroes in the United States in current population reports. Washington, DC, Superintendent of Documents, Series P-23: No. 24, 1967

6. Duncan OD: Discrimination among Negroes. Ann Am Acad Polit Soc Sci 371: 85-103, 1967

7. Detroit Urban League, Research Department: The Detroit Low-Income Negro Family. 1966

8. Erfurt J, Harburg E, Rice R: A method for selection of census tract areas differing in ecological stress (multilith report)

9. Harmon HH: Modern Factor Analysis. Chicago, University of Chicago, 1960

10. Report of the National Advisury Commission on Civil Disorders. New York, Bantam Books Inc, 1968

11. Cobb S, Harburg E, Tabor J, et al: The intrafamilial transmission of rheumatoid arthritis-I. Design of the study. J Chron Dis 22: 195-203, 1969

12. Aiken MT: Kinship in an Urban Community, $\mathrm{PhD}$ Dissertation. University of Michigan, Dept of Sociology, 1964

13. Stamler R: Racial Differences in Heart Disease Risk Factors-Some Sociopsychological Aspects, MA Thesis. University of Chicago, Dept of Sociology, 1962

14. Schull WJ, Harburg E, Erfurt J, et al: A family set method for estimating heredity and stress-II. Preliminary results of the genetic methodology in a pilot survey of Negro blood pressure, Detroit, 1966-1967. J Chron Dis 23: 83-92, 1970

15. Reed ET: Caucasian genes in American Negroes. Science 165: 762-768, 1969 